\title{
O.JS

\section{“TODO HOMEM TEM DIREITO A INSTRUÇÃO": UMA ANÁLISE DA EDUCAÇÃO BRASILEIRA ENTRE DÉCADAS SOB O OLHAR DE GILBERTO DIMENSTEIN AOS DIAS ATUAIS}

\author{
João Paulo Teixeira Viana ${ }^{1}$ \\ 1 Mestrando Profissional em Geografia pela Universidade Federal do Rio Grande do Norte (UFRN). E-mail: \\ jpviana25@yahoo.com-ORCID iD: http://orcid.org/0000-0002-3386-7992.
}

Artigo recebido em 14/04/2020 e aceito em 02/06/2020

\begin{abstract}
RESUMO
O presente artigo tem por objetivo construir uma análise comparativa da educação brasileira através de dados entre décadas, utilizando como base o importante postulado intitulado "O Cidadão de Papel” do autor Gilberto Dimenstein, livro este que busca traçar a realidade da sociedade brasileira através de dados estatísticos da década de 90 acerca dos problemas que assolam o país. Assim, o trabalho tem em seu desenvolvimento a atualização e comparação entre os dados do livro de Dimenstein e as estatísticas atuais, todavia, direcionado para o aspecto que é retratado no livro, sendo a educação. Os dados foram coletados no Instituto Brasileiro de Geografia e Estatística (IBGE), em sua base de dados SIDRA, no Ministério da Educação (MEC), no Instituto Nacional de Estudos e Pesquisas Anísio Teixeira (INEP), e dentre outros. Por fim, com posse desses dados foi possível construir mapas comparativos da realidade educacional brasileira em temas como: analfabetismo, evasão escolar, número de matrículas no ensino básico, dentre outras temáticas, possibilitando compreender a educação brasileira entre duas distintas décadas. Como resultados esperados, os dados mostraram-se que a educação no Brasil apresentou grandes avanços sociais, principalmente naqueles relacionados ao analfabetismo, contudo, ainda se apresenta um quadro de desafios ainda a serem superados, e como veremos é através da educação que é possível o desenvolvimento de uma nação.
\end{abstract}

Palavras-chave: Educação. Cidadão. Dados estatísticos. Gilberto Dimenstein.

\section{BETWEEN LIMITS AND POSSIBILITIES OF SCHOOL GEOGRAPHY}

\begin{abstract}
This study aims to build a comparative analysis of Brazilian education through data from decades, using as a basis the important postulate entitled "The Citizen of Paper" by the author Gilberto Dimenstein, a book that seeks to trace the reality of Brazilian society through statistical data from the 1990s about the problems that plague the country. Thus, the work has in its development the updating and comparison between the data in Dimenstein's book and current statistics, however, directed to the aspect that is portrayed in the book, being education. The data were collected at the Brazilian Institute of Geography and Statistics (IBGE), in its SIDRA database, at the Ministry of Education (MEC), at the National
\end{abstract}


Institute of Studies and Research Anísio Teixeira (INEP), and among others. Finally, with this data it was possible to build comparative maps of the Brazilian educational reality in themes such as: illiteracy, school dropout, number of basic education enrollments, among other themes, making it possible to understand Brazilian education between two distinct decades. As expected results, the data showed that education in Brazil presented great social advances, especially in those related to illiteracy, however, there is still a picture of challenges to be overcome, and as we will see it is through education that the development of a nation is possible.

Keywords: Education. Citizen. Statistic data. Gilberto Dimenstein.

\title{
ENTRE LÍMITES Y POSIBILIDADES DE LA GEOGRAFÍA ESCOLAR
}

\begin{abstract}
RESÚMEN
Este artículo tiene como objetivo construir un análisis comparativo de la educación brasileña a través de datos entre décadas, basado en el importante postulado "O Cidadão de Papel” del autor Gilberto Dimenstein, un libro que busca rastrear la realidad de la sociedad brasileña a través de datos. estadísticos de los 90 sobre los problemas que aquejan al país. Así, la obra tiene en su desarrollo la actualización y comparación entre los datos del libro de Dimenstein y las estadísticas actuales, sin embargo, dirigida al aspecto que se retrata en el libro, que es la educación. Los datos fueron recolectados en el Instituto Brasileño de Geografía y Estadística (IBGE), en su base de datos SIDRA, en el Ministerio de Educación (MEC), en el Instituto Nacional de Estudios e Investigaciones Anísio Teixeira (INEP), entre otros. Finalmente, con estos datos en la mano, fue posible construir mapas comparativos de la realidad educativa brasileña en temas como: analfabetismo, deserción escolar, número de matrículas en educación básica, entre otros temas, permitiendo comprender la educación brasileña entre dos décadas diferentes. Como resultados esperados, los datos mostraron que la educación en Brasil mostró grandes avances sociales, principalmente en los relacionados con el analfabetismo, sin embargo, todavía hay un cuadro de desafíos por superar, y como veremos es a través de la educación que es posible desarrollo de una nación.
\end{abstract}

Palabras clave: Educación. Ciudadano. Datos estadísticos. Gilberto Dimenstein.

\section{INTRODUÇÃO}

A educação é fundamental para a transformação de uma nação. Os países que não valorizam a ética, o trabalho e a educação em geral, apresentam economia frágil, os rendimentos são inferiores, refletindo em todo segmento como: habitação, saúde, qualidade e expectativa de vida.

Dentro desse contexto, a pesquisa situa-se na análise comparativa de dados estatísticos educacionais entre a década de 90 no qual utiliza como base o livro "O Cidadão de Papel” de Gilberto Dimenstein em comparação com dados atuais concernentes à temática citada.

No que tange os aspectos metodológicos, a pesquisa é de cunho bibliográfico, tendo como principal aporte o livro "Cidadão de Papel" e, para a construção dos dados comparativos entre as décadas de 90 e os dias atuais, foi necessário coletar dados do Instituto Brasileiro de Geografia e Estatística (IBGE), em sua base de dados SIDRA, no Ministério da Educação (MEC), no Instituto Nacional de Estudos e Pesquisas Anísio Teixeira (INEP), todos estes, base para a elaboração dos mapas temáticos. 
Logo, a pesquisa está dividida em três momentos, onde primeiro busca compreender o livro "Cidadão de Papel” sob um enforque em seu contexto de desenvolvimento, em seguida analisar as principais acepções do livro citado relacionado a temática educação e por fim, através de uma análise comparativa compreender os aspectos educacionais brasileiros a partir de dados estatísticos entre a década de 90 e os dias atuais.

\section{O LIVRO “O CIDADÃO DE PAPEL” DE GILBERTO DIMENSTEIN}

O livro "O Cidadão de Papel” do autor Gilberto Dimenstein é uma obra desenvolvida na década de 90, onde busca retratar a realidade da sociedade brasileira, embora tendo como público alvo a população adulta, Dimenstein utiliza uma linguagem de fácil compreensão, levando para o público mais jovem a reflexão acerca dos principais problemas que assolam o país dentro daquele contexto, perpassando por diversas temáticas "problemas" que a sociedade brasileira passou e continua passando nos dias atuais.

O autor explica que o livro surgiu na década de 90, período em que ministrou uma palestra para adolescentes e percebeu a preocupação por parte dos jovens com o grande aumento da violência nas cidades, onde observou "a falta de informação e de reflexão que poderia levá-los a uma postura perigosa: o uso de mais violência" (DIMENSTEIN, 1993).

O postulado é dividido em onze temáticas que são problemas que assolam a realidade brasileira, temas que passam, desde a discursão da cidadania, violência, desemprego, até seu fechamento com a educação. Sendo a discursão da cidadania a principal mola propulsora da discussão do livro, buscando "desvendar as engrenagens que produzem este tipo de cidadania, essas engrenagens estão diante dos nossos olhos. Convivem com nosso dia-a-dia" (GUIZZO, 1993).

Dimenstein mostra o papel real de uma sociedade que produz crianças de rua e ressalta que essa situação "tenha se tornado uma coisa normal para as pessoas" elencando que a criança é o elo mais fraco e exposto da sociedade, e sendo assim, ao mesmo tempo, o futuro do nosso país. Onde, "nenhuma nação conseguiu ir em frente com progresso sem investir na educação, que é estar investindo no futuro do país" (DIMENSTEIN, 1993).

O autor inicia o livro com a "Cidadania", explicando que os meninos de rua são um dos sintomas da crise social, surgidos por causa da pobreza e da falta de educação do país, ocasionando que esses indivíduos entrem em um ciclo de incapacidade de progredir, mesmo com os direitos das 
crianças é uma problemática da realidade das famílias brasileiras. Nas palavras de Santana (2009), ser cidadão parte de uma concepção similar de Dimenstein, um sujeito dotado de direitos:

Ser cidadão é ter consciência de que é sujeito de direitos. Direitos à vida, à liberdade, à propriedade, à igualdade, enfim, direitos civis, políticos e sociais. Mas este é um dos lados da moeda. Cidadania pressupõe também deveres. O cidadão tem de ser cônscio das suas responsabilidades enquanto parte integrante de um grande e complexo organismo que é a coletividade, a nação, o Estado, para cujo bom funcionamento todos têm de dar sua parcela de contribuição. Somente assim se chega ao objetivo final, coletivo: a justiça em seu sentido mais amplo, ou seja, o bem comum. (SANTANA, 2009, p. 1).

Já Santos (2007), elenca que o espaço ao se entregar ao jogo de mercado consagra desigualdades e injustiças, disparidades seculares como a exemplo do caso brasileiro que é um país desigual com oportunidades concentradas "Olhando para o mapa do país, é fácil constatar extensas (...) áreas desprovidas de serviços essenciais à vida social e à vida individual. O mesmo, aliás, se verifica quando observamos as plantas das cidades em cujas periferias, apesar de uma certa densidade demográfica, tais serviços (educação, saúde, informação) estão desigualmente ausentes. É como se as pessoas nem lá estivessem.” (MACHADO, 2008).

No tema "Violência", Dimenstein mostra que muitas crianças fogem de casa pelo medo da agressão dos próprios pais, levando-as a entrarem para o mundo do álcool, drogas e prostituição, em um ciclo vicioso, vivo e real. Já em "População", o autor foca no nível instrucional das mães sobre a necessidade de higiene e saneamento básico, as campanhas educativas e informacionais, como exemplo, de doenças sexualmente transmissíveis, gravidez na adolescência, entre outros. Todavia, aponta o saneamento básico na prevenção de doenças, a questão da reciclagem do lixo, a poluição ambiental e o tratamento da água.

Dessa maneira, a obra é um importante livro que pode ser estudado em diferentes momentos em sala de aula, por abordar vários assuntos complexos e por serem todos debatidos em um único livro. Pois, falar da realidade brasileira passa a ser o fio condutor de todo o processo de compreensão dos diversos problemas seculares que a sociedade brasileira vivência, onde, a solução central está na necessidade de investir na educação, e por conseguinte é através dela que será possível o desenvolvimento e crescimento de uma nação. 
Revista Ensino de Geografia (Recife) V. 3, No. 2, 2020

DOI: http://doi.org/10.38187/regeo2020.v3n2id244389

\title{
TODO HOMEM TEM DIREITO A EDUCAÇÃO: UMA ANÁLISE COMPARATIVA DOS DADOS ESTATÍSTICOS EDUCACIONAIS (DÉCADA DE 90 E DIAS ATUAIS)
}

\begin{abstract}
A família é pobre. Mora numa casa onde não tem saneamento básico. $\mathrm{O}$ ambiente facilita a transmissão de doenças. As doenças enfraquecem o corpo, que fica desnutrido. A criança desnutrida não aprende direito o que é ensinado. E quem não estuda não consegue arrumar um bom emprego. (DIMENSTEIN, 1993, p. 100).
\end{abstract}

É dentro desse contexto que Dimenstein finaliza seu livro, retratando e correlacionando os problemas educacionais e a própria educação como finalidade para se sair dessas letargias sociais. Além disso, aponta da necessidade do Brasil em investir na educação como motor para um país em desenvolvimento, fazendo assim, que as pessoas passem a saber seus direitos e obrigações e que possam ter melhor qualidade de vida.

Assim, partido desse pressuposto, o autor coloca exemplos clássicos de países que conseguiram desenvolver e crescer pautado no investimento educacional, como, por exemplo, dos países asiáticos que estiveram em "situação parecidas com a do Brasil, mas em vinte anos, entre 1950 e 1970, o analfabetismo caiu de 78\% para 11\%" (DIMENSTEIN, 1993). Vale salientar que investir em educação não é apenas uma questão de cidadania, como bem frisa o autor, mas apresenta um impacto na economia, pois se o grau instrucional do trabalhador aumentar, irá influenciar diretamente no aumento da produtividade. Como salienta Machado (2009), quando coloca a educação como um produto de reprodução social:

A educação foi por muito tempo, e ainda é, uma reprodutora da ordem social, intensificando a divisão do trabalho, de classes, e das fragmentações sociais, exatamente por estar ela também inserida no modo de produção que delineia as principais forças de ações e processos no espaço.

Contudo, para construção dos principais problemas educacionais no Brasil na década de 90, Dimenstein utiliza alguns parâmetros importantes para se discutir tal temática, sendo, o número de matriculas no ensino básico; a taxa de evasão escolar; o nível de qualificação dos professores e, por fim, a taxa de analfabetismo, condicionantes vitais para a discursão dos problemas educacionais.

Diante disto, foi necessário construir uma análise comparativa dos dados da década de 90 com as estatísticas atuais, no que tange a compreensão das realidades brasileiras nos períodos distintos citados. Além de verificar se houve neste meio tempo uma real melhoria nos índices e respectivamente na realidade educacional do Brasil. 


\section{NÚMERO DE MATRICULAS DO ENSINO BÁSICO}

O direito a educação é um preceito básico de todo e qualquer cidadão, é um direito constitucional, embora, segundo Dimenstein, na década de 90 o número de matrículas no ensino básico havia aumentado, tendo no ano de 1999 um total de 48.730 .232 milhões de crianças matriculadas no ensino básico. Contudo, apensar do aumento significativo, havia uma grande problemática quando 2,5 milhões de crianças brasileiras nunca colocaram os pés na escola.

O mapa a seguir demonstra a nível comparativo do número de matrículas no ensino básico entre o ano de 1999 e 2017 (último dado divulgado pelo o Educa Censo), onde se observa o comportamento entre as unidades federativas entre os anos citados.

Figura 1: Mapa do número de matrículas no ensino básico (1999 e 2017).

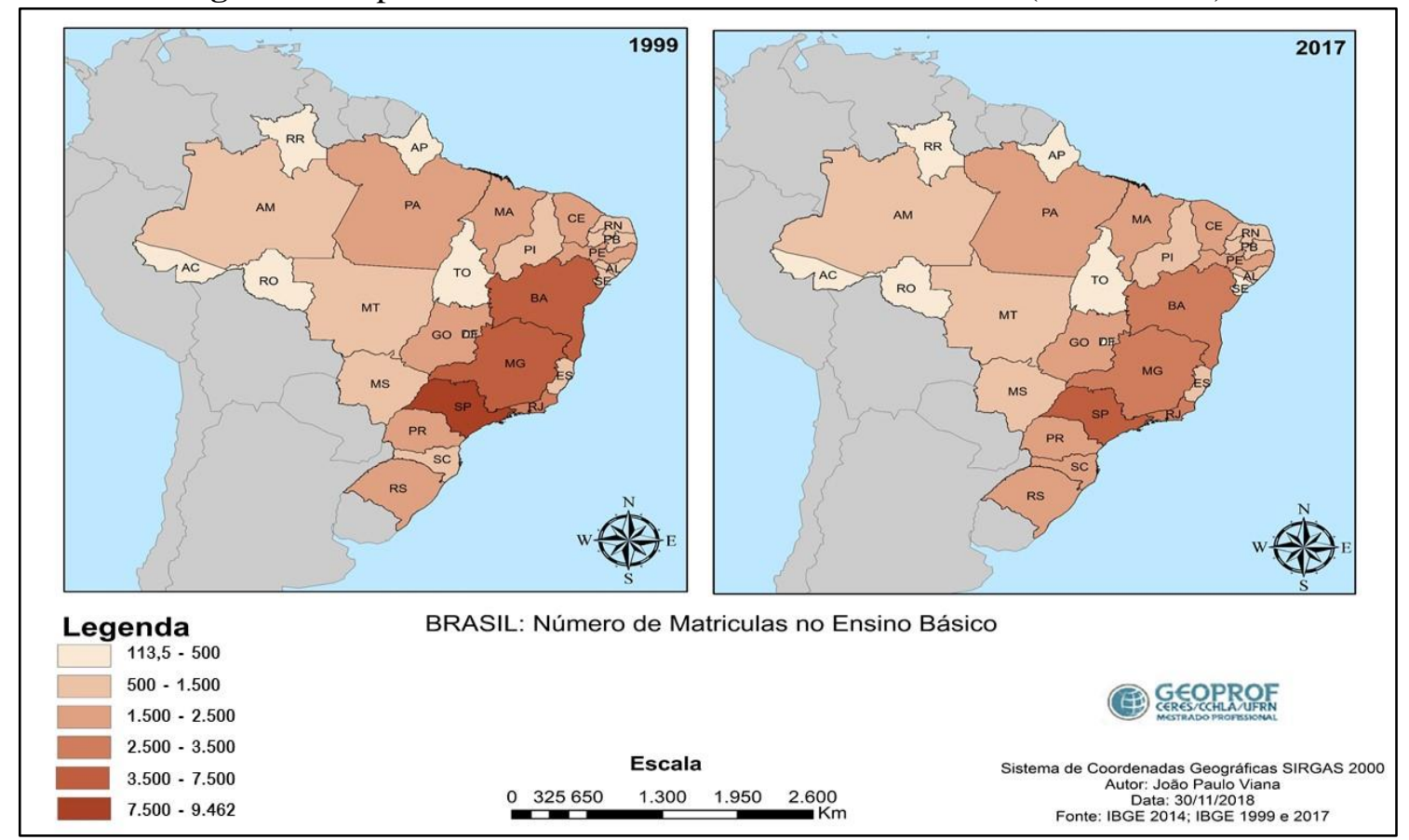

Fonte: Elaborado pelo o autor, baseado nos dados do IBGE e Educa Censo 2017.

De acordo com as estatísticas do Educa Censo, em 2017 foram registradas 35.278.424 matrículas no ensino básico. O número é menor quando comparado com o ano de 1999. A explicação para essa redução está relacionada principalmente à mudança no perfil demográfico da população entre os anos distintos, principalmente com menos crianças ingressando na etapa do fundamental anos iniciais. 
Como pode ser observado na Figura 2, relacionado as pirâmides etárias dos referidos anos, observa-se que houve um aumento populacional, entretanto, a população de adultos apresentou um "afrouxamento" e dá-se por conta pelo o envelhecimento, bem como, da redução da taxa de natalidade que seguindo outros parâmetros mundiais, a tendência de um menor número de filhos por habitante. Outro fator que pode explicar essa redução é o melhoramento em anos do fluxo escolar, ou seja, relacionado as taxas de aprovação em que mais alunos têm conseguido se formar e não ficar repetindo a mesma etapa como poderá ser visto no tópico "Evasão escolar".

Quando se observa as unidades federativas entre os períodos distinto, há um declínio no estado de São Paulo que é responsável pelo o maior número de matriculados no ensino básico, saltando de 9.462.328 em 1999, para 7.078.755 em 2017, deixando o estado isolado no mapa (Figura $1)$.

Figura 2: Pirâmide etária comparativa entre 1999 e 2017

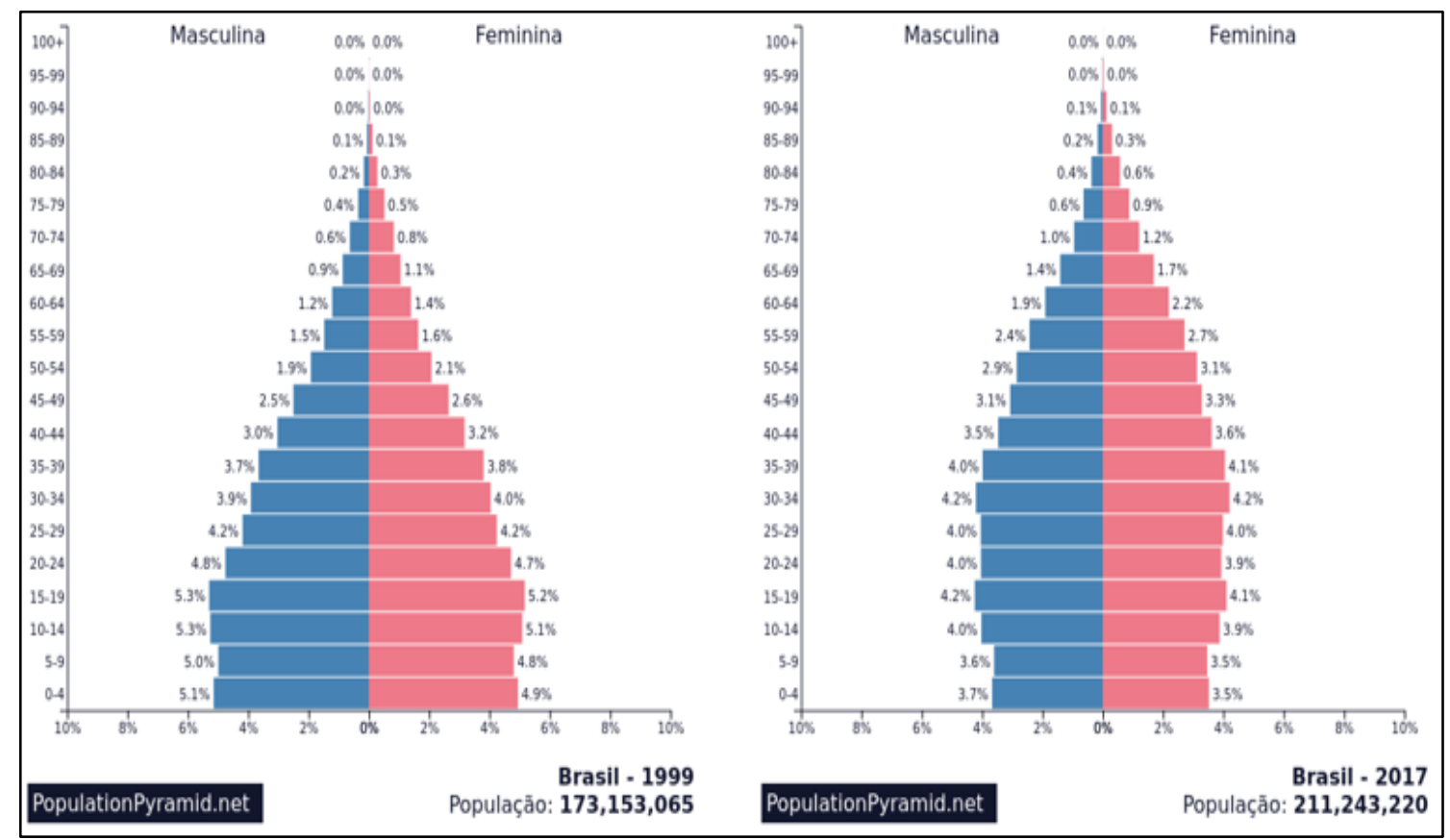

Fonte: Elaborado pelo o autor a partir do site Population Pyramid, acesso em 16 de junho de 2019.

Ainda assim, temos na região Norte, embora apresente um quadro estático, foi neste que os estados apresentaram uma elevação, a exemplo, o Acre e o Amazonas que teve um aumento de 7\% no número de matriculados no ensino básico em 2017.

Por fim, cabe relembrar o elucidado pelo o autor, onde 2,5 milhões de crianças não colocaram os pés nas escolas na década de 90 , infelizmente, é um quadro que persiste quando olhamos 
o levantamento feito pelo Todos Pela Educação que se baseia nos resultados da Pesquisa Nacional por Amostra de Domicílio (Pnad).

O Brasil possui 2.486.245 crianças e adolescentes de 4 e 17 anos fora da escola, um número alarmante quando comparamos períodos distintos e que o problema persiste mesmo com as políticas públicas voltadas à área da educação básica - transporte escolar, livros, uniformes, bibliotecas e alimentação.

\section{FREQUÊNCIA ESCOLAR}

Um segundo indicador importante quando se analisa a educação brasileira é a taxa de frequência escolar, pois nem sempre o número de matriculados em uma determinada escola é a realidade de alunos que estejam frequentando. Quando relacionado à frequência escolar existem dois parâmetros de análise, sendo: a taxa de frequência bruta (razão entre o número total de matrículas (independente da faixa etária) e a população correspondente na faixa etária prevista (15 a 17 anos) para o curso na etapa de ensino), e a taxa de frequência líquida representa a razão entre o número de matrículas de alunos com idade prevista (15 a 17 anos) para estar cursando determinada etapa de ensino e a população total na mesma faixa etária. No caso da análise deste artigo, é relacionada a taxa de frequência bruta.

Na década de 90 a taxa de frequência escolar no Brasil para o ensino básico era de $65 \%$ segundo dados do IBGE (series e estatísticas), atualmente a frequência está em torno de $85 \%$, dados divulgados pela Pesquisa Nacional por Amostra de Domicílio (Pnad). Na Figura 3, encontra-se um mapa comparativo entre o ano de 1991 e 2015, relacionado a taxa de frequência escolar. 
Figura 3: Mapa da Taxa de Frequência Escolar (1991 e 2015)

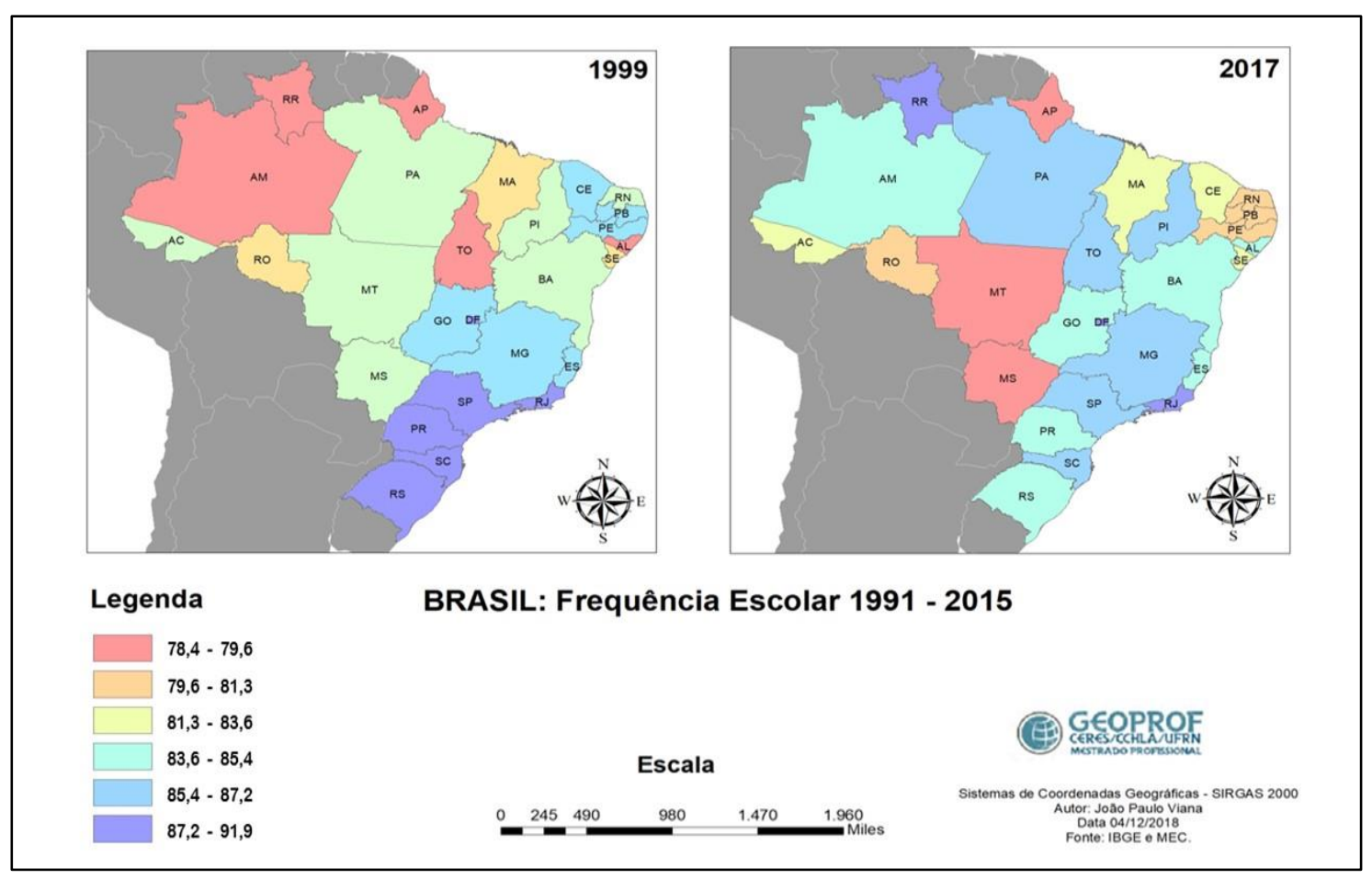

Fonte: Elaborado pelo o autor, baseado nos dados do IBGE e Educa Censo 2017.

Quando se analisa o mapa da frequência escolar na década de 90, observa-se uma elevação nas regiões Sul e Sudeste com média de $72 \%$ maior que o percentual nacional, nos dias atuais esse valor aumenta proporcionalmente, não apenas nestas regiões, mas em todo o Brasil.

O caso de maior alteração no quadro está no estado do Amapá, onde em 1991 detinha um percentual de $49 \%$ de frequência escolar, década depois a taxa aumenta para $79 \%$, isto pode ser explicado pelas diversas políticas públicas educacionais que proporcionaram o aumento da frequência escolar, principalmente nas regiões Norte e Nordeste. Assim, podemos destacar o programa do transporte escolar que possibilitou a mobilidade de estudantes localizados a quilômetros do espaço escolar, da alimentação na escola, como também, na valorização do professor que tem consequências positivas diretamente no fazer pedagógico deste profissional e na aprendizagem do aluno.

Contundo, embora a frequência escolar no Brasil entre décadas teve um real crescimento significativo em todas as unidades federativas, nem todos que frequentam premassem durante todo o período letivo, e como vimos, o número de matriculas não traz à realidade de quem esteja realmente em sala de aula, todos esses condicionantes provocados pela a evasão escolar, onde a realidade se aflige e dá as caras aos problemas educacionais brasileiros. 


\section{EVASÃO ESCOLAR}

Segundo Dimenstein (1993) “a indicação mais fiel da desigualdade social está nos índices de repetência e evasão". É um indicador que requer atenção quando se trata de políticas educacionais, mas para além disso, é um indicativo da dificuldade dos alunos de se manterem estimulados no processo de aprendizagem e de prosseguirem na escola.

De cada cem crianças que entram na primeira série do primeiro grau, apenas vinte chegam à oitava série. Há uma relação entre evasão e condições de vida dos pais. Os mais pobres exigem que o filho gere renda.

Dentro desse contexto, os dados comparativos são do ano de 1999, recolhidos das Series e Estatísticas do IBGE em comparativo com os dados divulgados pelo o Ministério da Educação (MEC) através do Educa Censo do ano de 2016.

A Figura 4, traz a taxa de evasão escolar através de um mapeamento especializados por unidade federativas, compreende o ano de 1999 e 2016. Quando observado é perceptível a redução da evasão escolar entre as décadas analisadas.

Vale ressaltar que, a evasão está ligada a repetência e ao consequente atraso escolar. O Brasil até recentemente (em 2000) figurava nas estatísticas como a exemplo da Unesco, entre os dez países do mundo com maiores taxas de reprovação no ensino fundamental e que, respectivamente, refletia no atraso escolar.

Outro dado importante citado pelo o autor, está relacionado entre as desigualdades sociais como um reflexo da evasão e reprovação. Segundo dados do Ministério da Educação que consta no livro "O Cidadão de Papeis", os quais apontavam que dois alunos a cada três em uma turma de qualquer série, ser repetente, ou seja, um aluno reprovado. 
Figura 4: Mapa da Taxa de Evasão Escolar entre 1999 e 2016

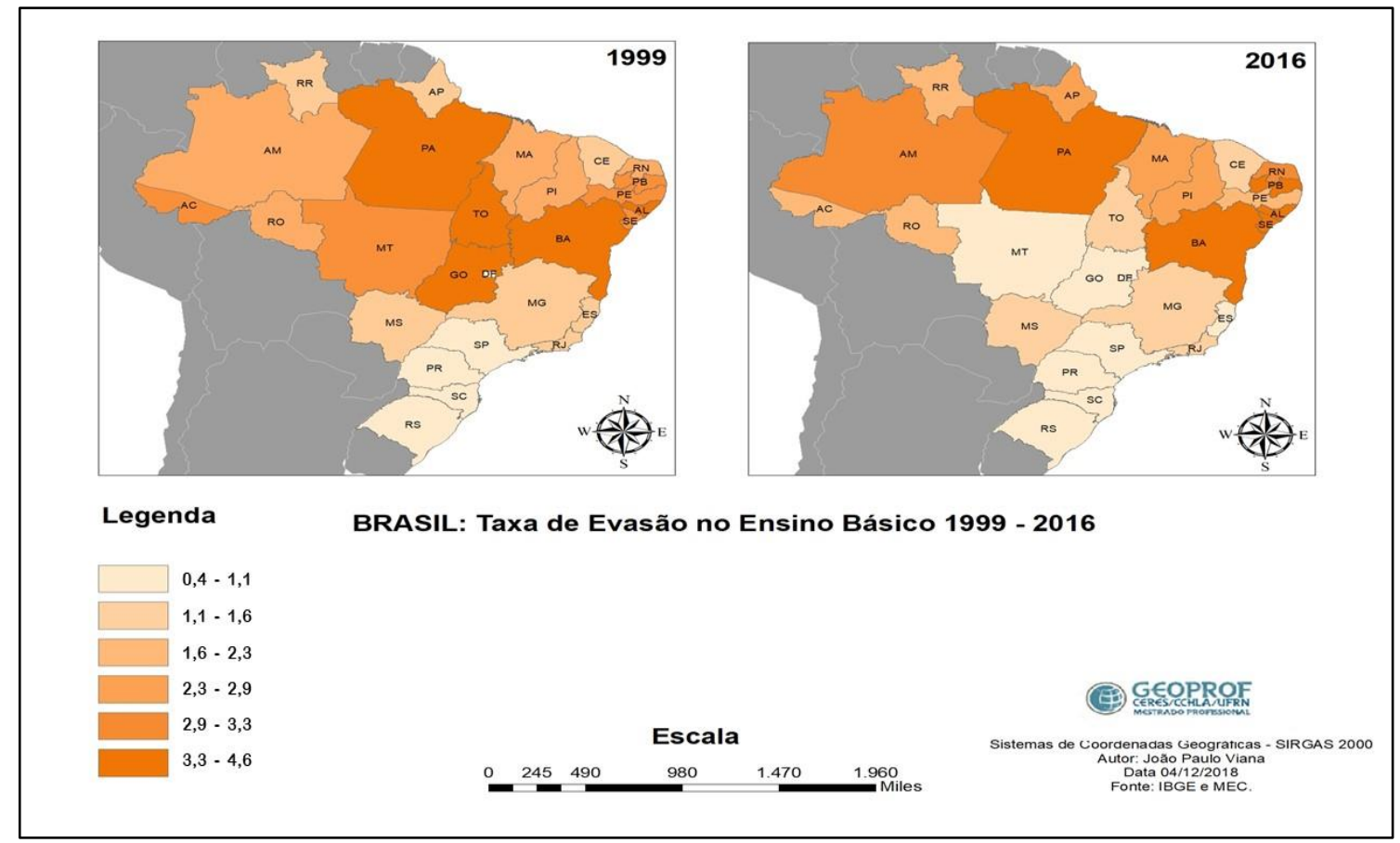

Fonte: Elaborado pelo o autor, baseado nos dados MEC e Educa Censo 2017.

Outro fator relacionado a essa reprovação está ligado diretamente com a evasão, uma vez que o aluno, após repetir várias vezes, desmotivado, abandona a escola, muitas vezes sem saber ler ou escrever na forma mínima para não ser considerado analfabeto. Com isto, a evasão deve ser tratada como um caso mútuo da vivência familiar (seu histórico e sua vida cotidiana) e nas suas relações com a escola (o papel que o aluno desempenha no espaço escolar e como a instituição lida com seus condicionantes reais familiares e citadinos).

Portanto, embora o contexto da escrita do livro apresentar dados alarmantes para a época, em comparação aos dados do ano de 2016, que o indicador tendeu a cair e esse quadro de evasão passa a se atenuar atualmente, seja pelos fatores governamentais através das políticas públicas e dá pressão da sociedade civil por melhorias.

Ainda assim, é necessário destacar que apensar dos indicadores apesentarem uma melhoria, segundo a UNESCO, o Brasil tem a terceira maior taxa de evasão escolar do mundo, ou seja, é algo necessário ser discutido por todos, seja pela a família, pelas instituições governamentais, ONGs e a própria escola. 


\section{> QUALIFICAÇÃO DOS PROFESSORES NO NÍVEL BÁSICO}

Segundo Dimenstein, outro indicador importante para se entender a educação brasileira, bem como, os principais problemas relacionados a esta temática, está na qualidade do ensino por parte dos profissionais da educação básica.

Primeiramente, deve-se ressaltar uma importante informação que o autor citado elenca, relacionando o nível de ensino e a qualidade do professor, isto é, seu nível formativo é um reflexo do salário que este recebe. Na Figura 5 está espacializado quantidade de professores do ensino básico que possuem nível superior (graduação), entre 1999 e 2017.

Figura 5: Mapa Qualificação dos professores do ensino básico 1999 e 2017

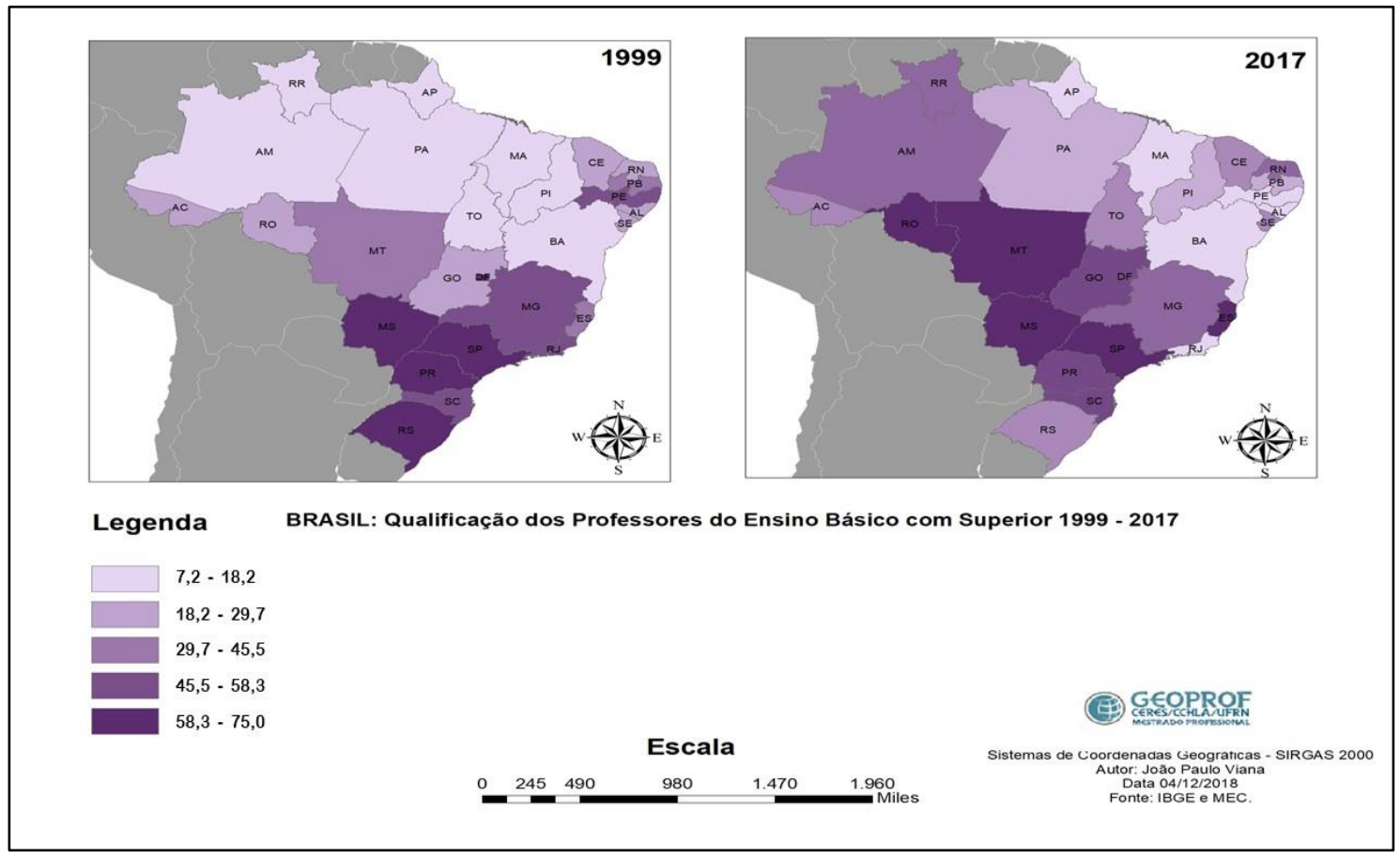

Fonte: Elaborado pelo o autor, baseado nos dados IBGE e Educa Censo 2017.

Segundo o Ministério da Educação, o salário médio de um professor na década de 90 com nível universitário girava em torno de US\$ 150. Os menos qualificados recebem por volta de US\$ 80 . Segundo dados da OCDE em 2016 o professor brasileiro recebia algo em torno de US\$650,00 mensais, número bem superior ao praticado na década de 90. Isto é explicado mediante as políticas de valorização e qualificação do professor iniciados nos anos 2000, o melhoramento do salário mínimo, dentre outros fatores que colaboram para essa alteração do quadro, embora não de forma 
exponencial, mas para a realidade brasileira quando se observa o contexto histórico neste âmbito, o professor nunca ganhou tão bem como nos aos 2000 e anos subsequentes.

Assim, como citado pelo o autor, "a remuneração acaba determinando a qualificação". Na década de 90 , somente $37 \%$ dos professores fizeram curso superior e 14,3\% têm apenas o primeiro grau completo. Com segundo grau completo são 46,4\%. É perceptível quando se observa o mapa sobre o nível de qualificação do professor nos fins dos anos 90 (ver Figura 5). Quando apenas o Distrito Federal detinha o maior percentual de professor do ensino básico com nível superior, bem diferente do ocorrido na região norte que contava com os menores índices de educadores com nível superior.

Nos dias atuais, o estado do Maranhão é o que apresenta o menor índice de professores do ensino básico com nível superior, mas ao observar os anos comparados, apresenta um crescimento de forma gradual, mas é insuficiente para a realidade encontrada nos demais estados brasileiros.

\section{TAXA DE ANALFABETISMO}

Conceitualmente, a taxa de analfabetismo é medida a partir do percentual de pessoas com 15 e mais anos de idade que não sabem ler e escrever pelo menos um bilhete simples no idioma que conhecem, na população total residente da mesma faixa etária, em determinado espaço geográfico, no ano considerado. Entretanto, segundo Dimenstein, é polêmica a definição de analfabetismo, por existir estudos indicando que quem não foi pelo menos quatro anos à escola pode ser considerado um analfabeto de fato.

Dessa forma, segundo os dados do autor citado, baseado nestes critérios na década de 90, $41 \%$ dos brasileiros poderiam ser considerados analfabetos, ainda acrescenta, quando essa taxa apresenta um teor político que:

A democracia é o regime que garante a liberdade de todos escolherem seus governantes. Mas só existe liberdade quando se pode optar. E só existe opção quando se tem informação. A capacidade de um analfabeto ter informação é muito limitada. Ninguém pode dizer que é livre para tomar o sorvete que quiser, se conhecer apenas o sabor limão. (DIMENSTEIN, 1993, p. 103).

Logo, o autor critica quando relaciona o fator político ao nível de compreensão dos candidatos em um determinada eleição, em saber suas propostas e seu passado político, mas que essa 
desinformação é vista tanto por parte dos ditos letrados como dos analfabetos, ou seja, uma pessoa desinformada não precisa ser apenas uma analfabeta ou não.

Dentro deste contexto, se faz necessário comparar e compreender a taxa de analfabetismo na década de 90 em comparação com os dados divulgados pelo o MEC em 2017. Se na década de 90 a taxa de analfabetismo esbarrava na casa dos $20 \%$ da população, quer dizer que esse total se encaixava na categoria de analfabetos ou em números absolutos, quase 20 milhões de pessoas segundo o Censo do IBGE de 1991.

Figura 6: Mapa da Taxa de Analfabetismo em 1990 e 2017

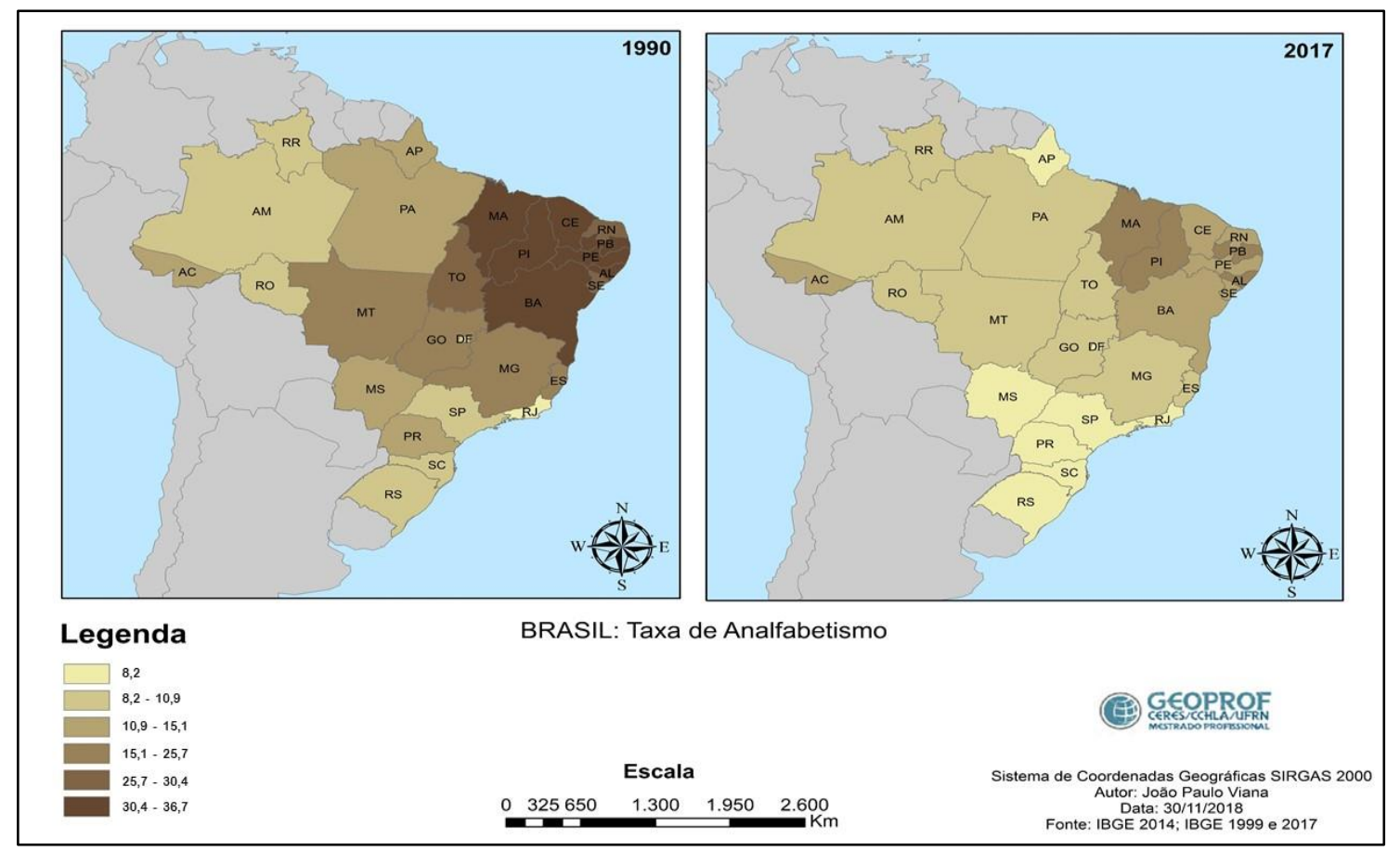

Fonte: Elaborado pelo o autor, baseado nos dados IBGE e Educa Censo 2017.

Nos dias atuais, a taxa de analfabetismo medido no ano de 2017 é de 7,2\%, correspondendo em números absolutos em 11,8 milhões de cidadãos brasileiros analfabetos. Em níveis de Brasil, observa-se uma redução do índice citado, entretanto é necessário se ater que está taxa apresenta uma flutuação conforme o crescimento populacional, sendo um outro condicionante a ser levado em conta para compreender a taxa de analfabetismo nos dois períodos distintos. Na Figura 6, relacionado ao mapa por unidades da federação acerca da taxa de analfabetismo em 1991 e 2017.

Quando se observa o mapa (figura 6) é perceptível que houve em todo os estados uma redução da taxa de analfabetismo, com destaque para a região Sul e São Paulo que conseguiram baixar 
os índices para menos de 5\% o nível de analfabetos nas populações desses Estados. Entretanto, é um quadro contrário na região Nordeste, que ainda detém o maior percentual de analfabetos no Brasil, destaque para Alagoas (18,2\%); Maranhão (16,7\%) e Piauí (16,6\%). Número superior duas vezes a média nacional.

Portanto, embora o Brasil apresenta uma taxa de analfabetismo menor que a comparada com a década de 90, o mesmo não conseguiu alcançar uma das metas estabelecidas pelo Plano Nacional de Educação (PNE) em relação a alfabetização da população com 15 anos ou mais. Na meta 9 do PNE determinava a redução do analfabetismo a 6,5\% até 2015, o que não ocorreu. Contudo, a Lei elenca que até o ano de 2024 o analfabetismo deva estar erradicado do país.

\section{CONSIDERAÇÕES FINAIS}

Depreende-se que a educação brasileira na década de 90 apresenta algumas transformações em sua estrutura normativa quando relacionado as reformas educacionais a exemplo da Lei de Diretrizes e Bases da Educação (Lei 9393/96), como também os Parâmetros Curriculares Nacionais, dentre outras políticas.

Contudo, Gilberto Dimenstein, em sua obra, mostrava um Brasil em termos educacionais que estava com grandes problemas em sua estrutura, existência de disparidades regionais quando se olha os índices por regiões e um país com altas taxas de evasão e repetência escolar como seus principais gargalos.

De um outro lado, tínhamos um país com poucos professores no ensino básico com nível superior/magistério, o que atenuava mais ainda a problemática educacional, uma vez que a falta de formação destes profissionais comprometia o processo de ensino e da aprendizagem do educando, onde por não aprender, ou por condicionantes familiares, pessoais, entre outros, largavam a escola. Quando se olhava para a família deste aluno, víamos que boa parte era analfabeta, fazendo e compondo as altas taxas de analfabetismo no Brasil.

Sendo assim, Dimenstein mostrava o Brasil em uma realidade não muito diferente dos dias atuais, embora as políticas públicas educacionais dos anos 2000 para hoje tenham atenuado diversos gargalos no sistema educacional, como: a redução do analfabetismo e da evasão escolar, bem como, o alto número de professores do ensino básico com nível superior. Todavia, nem tudo está sanado, mas sim, em processo. Embora os índices comparativos entre as décadas sejam satisfatórios, o Brasil ainda peca na velha história, no mesmo sistema educacional que não busca formar individuo para 
exercer sua cidadania conhecendo seus direitos, mas, formar um cidadão "maquina" para o mercado de trabalho, onde seu objetivo central em toda a sua vida escolar é ser mais um integrante da mão de obra capitalista.

Desse modo, algo a importante Dimenstein deixa em sua obra muito além da forma explicativa e da linguagem clara utilizada no livro, mas quando ele elenca repetidas vezes a necessidade do investimento na educação como forma de sair da letargia de diversos problemas brasileiros, pois, quando se investe em um aluno, está tirando um indivíduo da criminalidade, está dando a oportunidade de ser e exercer sua cidadania, está na possibilidade de abrir um leque de informações sociais e direitos que poucos sabem que existe e que tem "por direito". É através da educação que é possível crescer e desenvolver o homem, fazer dele o agente da sua própria vida e ser um cidadão responsável pela a história do seu país.

\section{REFERÊNCIAS}

BRASIL. Remuneração: Inep divulga estudo sobre salário de professor da educação básica. 2017. Disponível em: <http://portal.mec.gov.br/busca-geral/222-noticias/537011943/50471-inep-divulgaestudo-sobre-salario-de-professor-da-ducacao-basica>. Acesso em: 05 dez. 2018.

IDEB: O que é o IDEB. 2015. Disponível em: <http://portal.inep.gov.br/web/guest/ideb>. Acesso em: 05 dez. 2018.

IDEB: Apresentação. 2015. Disponível em: <http://portal.mec.gov.br/conheca-oideb>. Acesso em: 05 dez. 2018.

- Instituto Brasileiro de Geografia e Estatística. 2017. Disponível em: <https://www.ibge.gov.br/>. Acesso em: 05 dez. 2018.

- Serie Estatísticas e Series Históricas - Instituto Brasileiro de Geografia e Estatística. 2018. Disponível em: <https://seriesestatisticas.ibge.gov.br/. Acesso em: 05 dez. 2018.

DIMENSTEIN, Gilberto. O cidadão de papel: a infância, a adolescência e os direitos humanos no Brasil. 3. ed. Ática: São Paulo, 1993.

MACHADO, Gregório Borges. Educação e Cidadania: A Formação Do Cidadão A Partir Do Ensino Da Geografia, A Possibilidade De Conhecimento Do Espaço A Partir De Sua Estrutura Normativa e Cidadania. UNB, 2008.

SANTOS, Milton. O espaço do cidadão. São Paulo: Nobel, 2007. 